\title{
BMJ Open Is the current level of training in the use of equipment for prehospital radio communication sufficient? A cross- sectional study among prehospital physicians in Denmark
}

To cite: Holm JH. Is the current level of training in the use of equipment for prehospital radio communication sufficient? A cross-sectional study among prehospital physicians in Denmark. BMJ Open 2017;7:e015017. doi:10.1136/ bmjopen-2016-015017

- Prepublication history and additional material is available. To view please visit the journal (http://dx.doi.org/ 10.1136/ bmjopen-2016-015017).

Received 13 November 2016 Revised 12 May 2017 Accepted 30 May 2017

\section{CrossMark}

${ }^{1}$ Department of Anesthesiology and Intensive Care, Mobile Emergency Care Unit, Odense University Hospital, Odense, Denmark

${ }^{2}$ Department of Anesthesiology and Intensive Care, Odense University Hospital, Odense, Denmark

Correspondence to Jimmy Højberg Holm; jimmy. hoejberg.holm@rsyd.dk

\section{ABSTRACT}

Background Physicians working in prehospital care are expected to handle radio communication both within their own sector as well as with other divisions of the National Emergency Services. To date, no study has been conducted on the level of training received by physicians in the use of the equipment provided or on the level of competency acquired by physicians.

Methods In order to investigate the self-assessed skill level acquired in the use of the TETRA (TErrestrial Trunked RAdio) authority radio for communication in a prehospital setting, a cross-sectional study was conducted by questionnaire circulated to all 454 physicians working in the Danish Emergency Medical Services.

Results A lack of training was found among physicians working in prehospital care in Denmark in relation to the proper use of essential communication equipment. Prior to starting their first shift in a prehospital setting $38 \%$ of physicians reported having received no training in the use of the equipment, while $80 \%$ of physicians reported having received one 1 hour of training or less. Among the majority of physicians their current level of training was sufficient for their everyday needs for prehospital communication but for $28 \%$ of physicians their current level of training was insufficient as they were unable to handle communication at this level.

Conclusion As the first study in its field, this study investigated the training received in the use of essential communication equipment among physicians working in prehospital care in Denmark. The study found that competency does not appear to have been prioritised as highly as other technical skills needed to function in these settings. For the majority of physicians their current level of training was sufficient for everyday use but for a substantial minority further training is required, especially if the redundancy of the prehospital system is to be preserved.

\section{INTRODUCTION}

Prehospital communication often takes place in hectic situations. Effective communication among Emergency Medical Services (EMS) as well as all branches of the Prehospital Emergency Services is essential for a
Strengths and limitations of this study

- This study is, to the best of our knowledge, the first in its field and a response rate of $74 \%$ increases the validity of the results.

- As the TETRA (TErrestrial Trunked RAdio) authority radio is in use in most of Europe for prehospital radio communication, the results of this study have broad relevance outside the context in which it has been done.

- The study has sought to include all physicians working at a 24/7/365 operational Emergency Medical Service in Denmark.

- The inherent bias in using self-assessments in studies is a known limitation.

- The study does not seek to show a causal relationship between an increase in the provision of formal training and an increase in the self-assessed levels of competence in using the equipment.

shared situational awareness and the efficient treatment of patients. ${ }^{1-3}$ In other settings, a significant correlation between a team leader's degree of situational awareness and critical task performance has been shown to exist, ${ }^{4}$ underlining the need for effective communication.

Physicians working in prehospital care are frequently required to make a large number of rapid decisions under intense pressuredecisions, which depend on the physician's situational awareness. During larger emergency operations, including those involving multiple operators (ie, police and fire departments as well as EMS), cooperation becomes an important part of the job; cooperation, which requires a shared situational awareness. A previous study by Seppänen et $a l^{2}$ identified several factors affecting the formation of a shared situational awareness in a prehospital context, including two influential factors: information gaps and a lack of fluent 
communication. In our view, both factors could arguably be ascribed to difficulties in communication. For these reasons, attaining proficiency in radio communication is essential for all staff working in EMS, including physicians working in prehospital care.

Following the terrorist attack on the World Trade Center in New York on 11 September 2001 and the incident in the Danish town of Seest on 3 November 2004, the need for secure radio communication among members of the Danish Emergency Services became apparent. ${ }^{5}$

As a consequence of these events the Danish government in 2010 implemented a new, secure communications network ('SIkkerhedsNEttet' aka 'SINE') based on the TETRA (TErrestrial Trunked RAdio) standard. ${ }^{67}$ This network is currently used by all Danish authorities involved in emergency communications (eg, ambulance services, police, fire and rescue services and the Danish Armed Forces) as a means of ensuring efficient and secure radio communication across these divisions.

Physicians employed in the Danish EMS are usually working only part-time within the EMS and, as a result, proficiency in radio communication can be difficult to obtain. At the time of our survey there were neither formalised regional nor national requirements in place for the proper use of radio communication equipment for physicians working in prehospital care, nor were there any training programmes available specifically tailored to physicians. Presently, the only formal way for physicians to gain experience in the use of the authority radio network is via a 3-week On-Site Medical Commander Course at the Danish Emergency Management Agency. However, for the vast majority of prehospital medical providers this course, apart from posing a major expense, covers a curriculum of radio communications far in excess of what would normally be required in the context of prehospital care.

A recent review of the literature concerning the use of simulation for training in prehospital care did not find any studies on the use of simulation in the field of radio communication. ${ }^{8}$ Enlisting the help of a medical librarian, MEDLINE, EMBASE and Web of Science were systematically searched for relevant articles concerning training in the field of prehospital radio communication. Additionally, Google and Google Scholar were searched, again to no avail, making this to the best of our knowledge, the first study in the field.

While training programmes relating to other technical areas of prehospital medicine are well known, ${ }^{9-11}$ to the best of our knowledge no training programme exists for the use of the communication tools available in a prehospital setting. The aim of this study is to evaluate the need for such a training programme. To do this, the current level of expertise among EMS physicians using the TETRA radio as a means of radio communication was examined by use of a cross-sectional survey.

Three objectives were specified:

The first objective is to quantify the amount of training received by physicians working in a prehospital setting.
The second objective is to assess the quality of training received by physicians.

The third objective is to investigate if training has any influence on physicians' level of competency in using the TETRA authority radio.

\section{MATERIALS AND METHODS}

A cross-sectional study was conducted of all physicians working in the Danish EMS on the amount of training received and the self-assessed skill level in using the TETRA radio for communication in a prehospital setting. The reporting of this cross-sectional study seeks to comply with the standards set out in the Strobe Statement. ${ }^{1213}$

All physicians working on Danish Rapid Response Vehicles (RRV) and the Danish Helicopter Emergency Services (HEMS) were included in the study, excluding those physicians who had not had a shift on their respective vehicles during the past 6 months. These physicians were deemed inactive and therefore excluded from the survey.

A questionnaire was developed concerning the different aspects of training received and the level of proficiency acquired in the use of the TETRA radio. The questionnaire was sent to all physicians in Denmark working either on a RRV or with the HEMS.

\section{Development of the questionnaire}

A self-assessment questionnaire was designed to determine the skill levels among physicians working in prehospital care in Denmark in the use of the TETRA radio. The questionnaire was developed based on existing literature and in accordance with normal practice. ${ }^{14-16}$

Software specific to questionnaire design (SurveyXact, Rambøll Management Consulting, Aarhus, Denmark, www.surveyxact.com) was used to create and distribute the questionnaire, as well as to collect and analyse the resulting data. A translated version of the questionnaire can be viewed in full in the online supplementary file.

Interviews with physicians working in a prehospital setting were initially undertaken in order to determine the relevant questions to ask concerning the type, level and availability of training in the use of the TETRA radio for prehospital radio communication. Based on these interviews, the questionnaire was subsequently developed and refined in accordance with feedback from the above-mentioned participants.

As many of the physicians working in prehospital care in Denmark have multiple employers, and due to the unspecific nature of email addresses, it is almost impossible to identify individuals with absolute certainty. Therefore, in order to avoid bias, the questionnaire needed to be designed to take this issue into account as we wanted only one response per prehospital physician.

A design formulation was selected which allowed respondents to specify whether their answers were provided in a primary prehospital capacity or in a secondary capacity, the primary capacity being defined as the one in which 
the physician worked the majority of hours per month. Answers given in any secondary prehospital capacity were registered but were not included in the final analysis.

The pilot questionnaire was tested for readability and user friendliness by 14 physicians representing the five regions of Denmark. Final adjustments were made to the questionnaire on the basis of answers and comments resulting from this pilot test.

\section{Main survey}

Email addresses for physicians working on Danish RRVs and the Danish HEMS were obtained from the offices managing each of the vehicles.

\section{Quantification of training received}

To quantify the amount of training received by prehospital physicians in the use of the TETRA radio, physicians were asked about the amount of formal training they had received. The question was threefold and divided into sections regarding training received prior to starting work in a prehospital setting; training received in the past year; and the total amount of training received.

\section{Quality of training received}

In order to evaluate the quality of the training received by prehospital physicians, a range of questions had to be answered. First, physicians were asked to self-assess their current level of expertise or competency in using the TETRA radio. The different levels of competency were defined in accordance with the Proficiency Scale outlined by the US National Institute of Health ${ }^{17}$ and each physician was asked to rate his or her own skill level in using the radio for communication in their everyday work by reference to a 5-point scale. The scale ranged from basic (level 1) to expert (level 5). Skill level 3 was defined as the ability to handle most communication on a daily basis, excluding communicating with multiple operators on the scene of a major disaster.

Second, physicians were asked about training received in the use of the TETRA radio, and asked to rate if their current level of training would be sufficient for simultaneously handling both radio communication and patient treatment.

Finally, physicians were asked to what extent their level of training was sufficient in order to:

1. concentrate on treating the patient;

2. do the job adequately;

3. handle radio communication at the scene of a major catastrophe.

\section{Effect of training}

In order to investigate if a correlation exists between the amount of training received in the use of the TETRA radio and the skill level acquired, hours of training received and self-assessed competency level were cross-referenced.

Blinding of the results at the individual level was done by the software used in such a way that no individual answer could be linked to any specific physician. The only information available to the author was whether or not a physician had answered the questionnaire, thus allowing for reminders to be sent but nothing more. The results of the survey are presented as descriptive data.

The project has been presented for approval at both The Regional Scientific Ethical Committees for Southern Denmark and at The Danish Data Protection Agency. Both organisations deemed approval unnecessary due to the design and nature of the study, in accordance with Danish law.

Permission to conduct the survey was granted by the offices managing each of the organisations in question. All answers from the survey were automatically anonymised and collected in such a way that no individual answer could be linked to any specific physician.

\section{RESULTS}

Questionnaires were sent to 457 unique email addresses on 22 September 2015. Follow-up emails were sent to 254 and 156 respondents on 30 September and 7 October 2015 , respectively. The survey was concluded on 27 October 2015.

Of the 457 potential respondents to the survey, three were excluded due to invalid email addresses, leaving 454 possible respondents. Of this number, 338 respondents (74\%) completed the survey. Three physicians subsequently asked to be removed from the survey as they no longer wished to participate in the study, 4 respondents answered the questionnaire only partially, and 109 physicians did not respond at all. Of the 338 completed questionnaires, 17 were received from physicians who had not worked in prehospital care over the course of the past 6 months. As previously stated, these questionnaires were excluded from the study. Of the remaining questionnaires, 58 were answered in a secondary prehospital capacity and were, as previously noted, excluded from analysis. Final analysis was done on the remaining 263 questionnaires. The flow of participants is shown in figure 1.

\section{Training received in the use of the TETRA radio for communication}

The self-reported amount of training received by each of the 263 participants in the survey is listed in table 1 . The amount of training is divided into three categories: the amount of training received prior to starting work in a prehospital setting; the amount of training received in the past year; and finally, the total amount of training received.

\section{Quality of training received in the use of the TETRA radio for communication}

Using the 5-point Proficiency Scale ${ }^{17}$ each physician was asked to rate his or her own skill level in the use of the TETRA radio for radio communication in their everyday work. The results can be seen in figure 2 .

The number of respondents at each level of the Proficiency Scale can be seen along with corresponding 


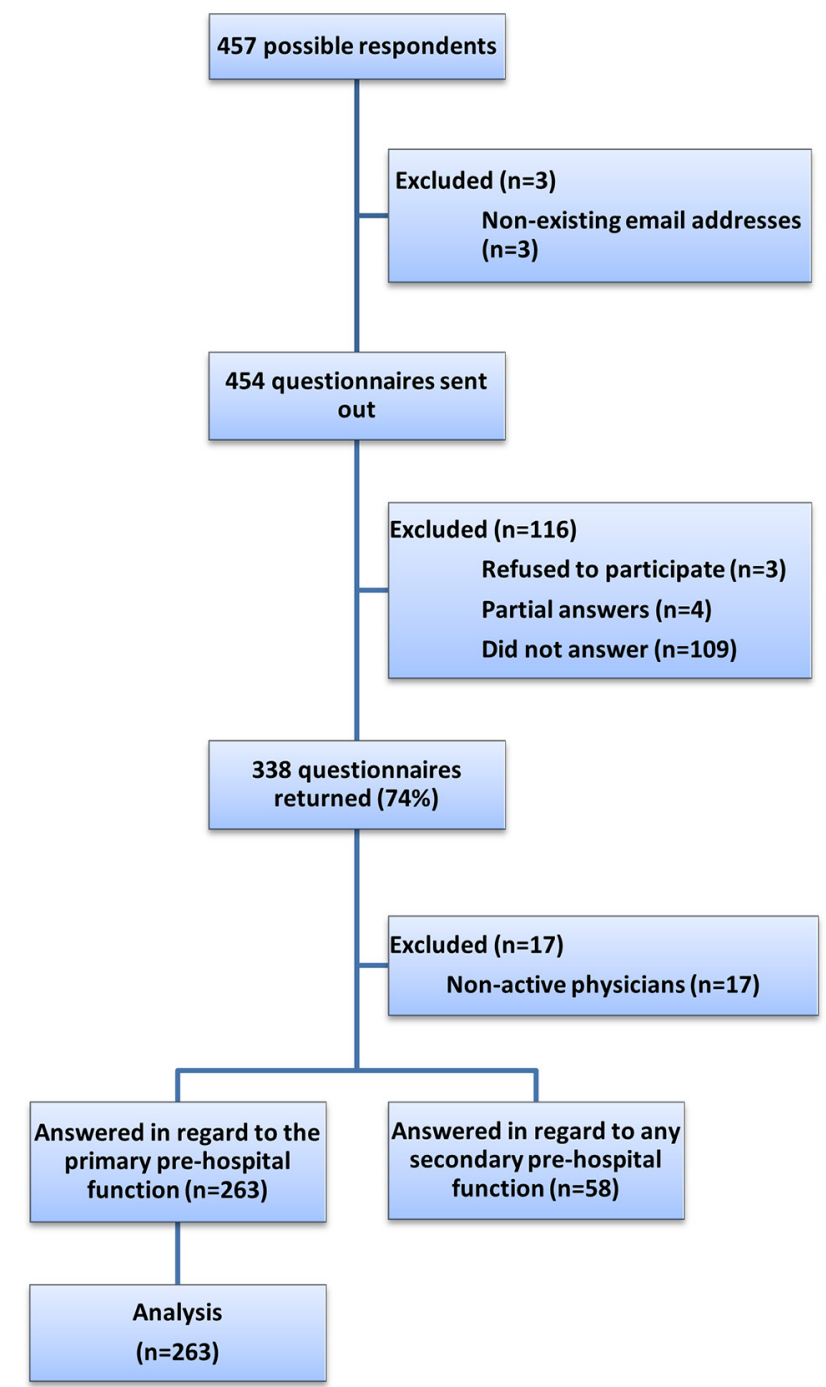

Figure 1 Flow diagram demonstrating the number of eligible respondents included in the study.

percentages. The scale ranges from basic (level 1) to expert (level 5), with level 3 corresponding to an ability to handle most communication at an everyday level, excluding radio communication at the scene of a major disaster involving communication with multiple operators

Table 1 Training received in the use of the TETRA radio

\begin{tabular}{llll}
\hline & $\begin{array}{l}\text { Training } \\
\text { received } \\
\text { prior to } \\
\text { starting in a } \\
\text { prehospital } \\
\text { setting }\end{array}$ & $\begin{array}{l}\text { Training } \\
\text { received } \\
\text { in the past } \\
\mathbf{1 2 m o n t h s}\end{array}$ & $\begin{array}{l}\text { Total } \\
\text { training } \\
\text { received }\end{array}$ \\
\hline Category & $100(38 \%)$ & $115(44 \%)$ & $27(10 \%)$ \\
\hline $\begin{array}{l}\text { No training } \\
\text { One hour of } \\
\text { training or less }\end{array}$ & $111(42 \%)$ & $104(40 \%)$ & $84(32 \%)$ \\
$\begin{array}{l}\text { More than 1 hour } \\
\text { of training }\end{array}$ & $52(20 \%)$ & $44(17 \%)$ & $152(58 \%)$ \\
\hline Total & $263(100 \%)$ & $263(100 \%)$ & $263(100 \%)$ \\
\hline
\end{tabular}

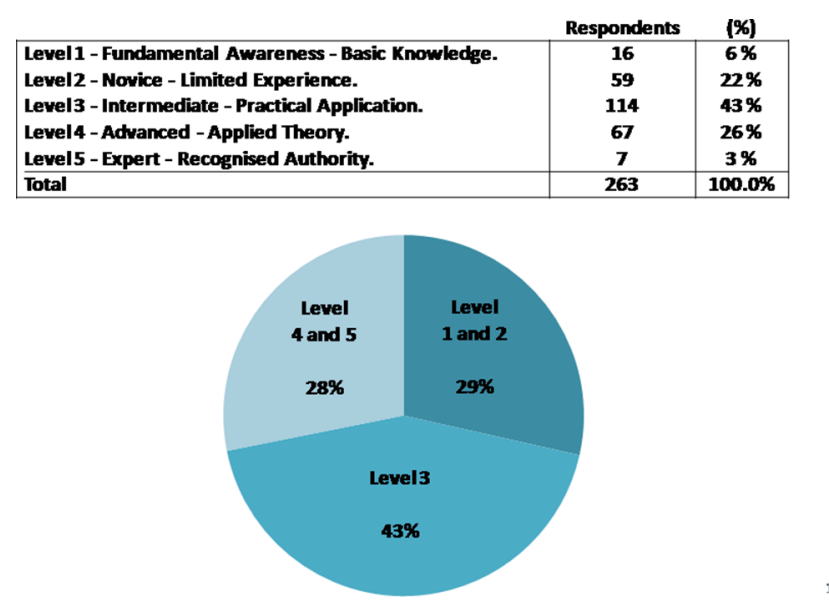

Figure 2 Self-assessed competences in using the TETRA radio. Figure showing self-assessed skill levels acquired by prehospital physicians using National Institutes of Health's 5-point Proficiency Scale. TETRA, TErrestrial Trunked RAdio.

including ambulances, helicopters, medical coordination and the police and fire departments.

Regarding the quality of the training received, respondents were asked to state the extent to which they agreed with various statements concerning sufficiency of training. They were asked if the level of training (1) would be sufficient to allow them to concentrate on treating patients, (2) would be sufficient to adequately do the job as a prehospital physician and, finally, if it (3) would be sufficient for the physician to handle radio communication at the scene of a major catastrophe, including the above-mentioned prehospital operators. The results can be seen in table 2 .

\section{Effect of training on self-assessed competency in using the TETRA radio for communication}

Results of cross-referencing the self-assessed skill levels in the use of the TETRA radio with the number of hours of training received are shown in figure 3 . The figure shows the distribution of the different levels of competency in using the radio (levels 1-5) in relation to the amount of training received in its use, ranging from no training to more than 5 hours of training. Numbers in the graph represent percentages of respondents at each level of training received.

\section{DISCUSSION}

This study describes the current levels of training and self-assessed competencies in the use of the TETRA radio for communication among physicians working in prehospital care in Denmark. Specifically, it investigates the amount of training physicians received and assesses the present levels of competency in using the radio communication tools provided. Finally, the study examines if a correlation between training and acquired competencies can be seen. It is, to the best of our knowledge, the first study to do so. 
Table 2 Physicians' statements regarding sufficiency of training

\begin{tabular}{lccc} 
Category & Sufficient to concentrate Sufficient to do $\begin{array}{l}\text { radio communication } \\
\text { at the scene of a major } \\
\text { catastrophe }\end{array}$ \\
\hline to a very great, to a great or to some extent & $172(65 \%)$ & $151(57 \%)$ & $178(68 \%)$ \\
\hline To a lesser or to no extent & $89(34 \%)$ & $108(41 \%)$ & $81(31 \%)$ \\
\hline Do not know & $2(1 \%)$ & $4(2 \%)$ & $4(2 \%)$ \\
Total & $263(100 \%)$ & $263(100 \%)$ & $263(100 \%)$
\end{tabular}

As seen in table 1 , the amount of training received by prehospital physicians in the use of the TETRA radio is generally quite low. Prior to starting the first shift in a prehospital setting, more than one in three physicians $(38 \%)$ reported that they had received no formal training in the use of the radio, while the great majority $(80 \%)$ reported having received 1 hour of training or less by way of introduction.

A similarly low percentage is seen in the amount of training received during the past year, as well as in total. Ten per cent of physicians reported having received no training at all in the use of the communication equipment provided. In total, the formal training received by physicians during their entire period of employment in prehospital care amounted to 1 hour or less for $42 \%$ of the survey respondents.

Training, either by simulation ${ }^{18} 19$ or by e-learning, ${ }^{20} 21$ has been shown to have a positive effect on technical skill competenciesacquired in otherareas of medical education, although in regard to e-learning the results are equivocal with studies also showing no effect of an e-learning programme as a booster of previously acquired competencies. $^{22}$ Little is known in regard to the amount of training needed in order to acquire and maintain competencies in the usage of the radio. However, studies on the effect of training in other technical skills are abundant. It has been shown that learning very basic surgical procedures is achievable with minimal time investment ${ }^{23}$ while more advanced competencies have required more extensive training. A training programme including $300 \mathrm{~min}$ of training on bench models has been shown to significantly improve surgical skills in laparoscopic cholecystectomy, ${ }^{24}$ and other training programmes have included training for more than 7 hours in order to show an acceptable level of competency. ${ }^{25} 26$

Regarding the self-assessed level of competency in using the radio for communication as seen in figure 2 , the study reveals that a large majority of physicians $(72 \%)$ are at

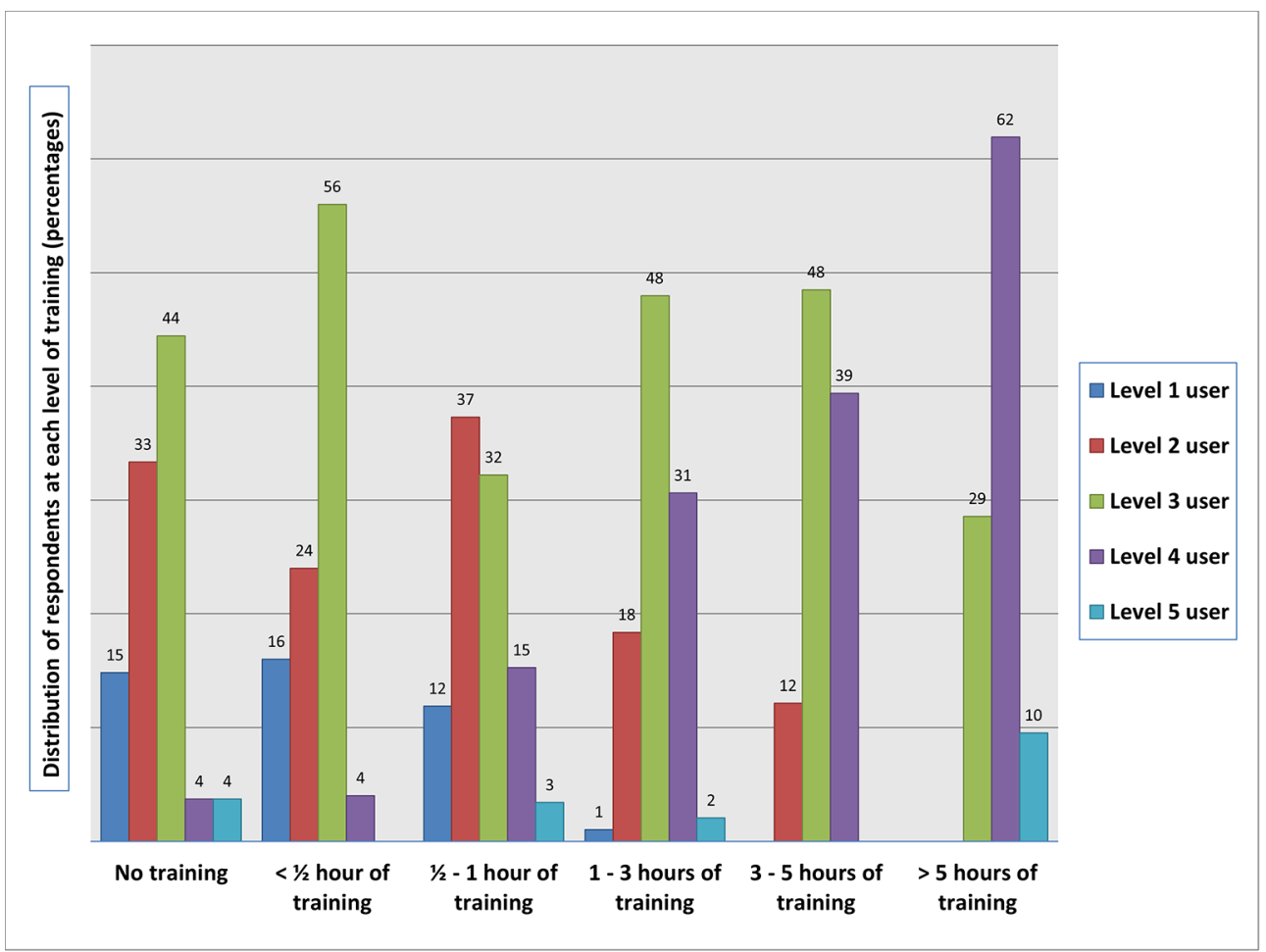

Figure 3 The effect of education. Figure showing the skill level acquired on the 5-point Proficiency Scale in relation to the amount of training received. Numbers represent physicians' distribution of competence (percentages) at that level of training. 
level 3 or above, corresponding to the ability to handle radio communication at least at a level sufficient for the everyday needs of prehospital physicians. However, almost a third of physicians $(28 \%)$ responded that they would not be able to handle radio communication at this level. For this to be of any significance, it is a prerequisite that the self-assessment of skills bears any resemblance to the actual level of competency. As previously noted, no studies were found on prehospital radio communication but a recent review has shown that evidence exists to support the reliability of self-assessment of technical skills in general surgery ${ }^{27}$ and there are no immediate reasons to assume that this would not also hold true for prehospital physicians.

While a majority of physicians have reached at least level 3 competency, indicating that the current level of training is sufficient to allow them to perform the tasks presented in table 2 , a substantial minority agrees only 'to a lesser extent' or 'to no extent.'

With regard to the ability to handle radio communication at the scene of a major disaster, including communication with multiple operators including ambulances, helicopters, medical coordination and the police and fire departments, approximately a third of physicians $(31 \%)$ stated that they would not be able to handle this type of communication, either at all or only 'to a lesser extent.'

The results are suggestive of a relatively high competency level in using the equipment for radio communication for a large proportion of physicians working in a prehospital setting; however, there is a potential lack of training for a substantial minority, which needs to be addressed.

In the Danish EMS, physicians (both in RRVs and HEMS) do not work alone but rather work in collaboration with paramedics. Paramedics could in theory, in addition to supporting patient treatment, handle radio communication thus leaving physicians to concentrate exclusively on the patient. However, choosing such an operating procedure for radio communication would diminish the redundancy in the system and leave it vulnerable to delays and loss of information as physicians would need to relay information via the paramedic.

Another problem arises relating to communication at major disasters. At present, the Danish EMS does not operate a national system that includes an On-Site Medical Commander for major disasters or terrorist incidents. Rather, there are regional differences in the handling of such incidents. In most areas, the RRV first at the scene is required to handle coordination of medical dispatch, ambulances and other operators, that is, the police and fire department, and in doing so is required to handle extensive radio communication at the site of the incident.

Although level 3 competency may suffice for the handling of radio communication on an everyday level, for most physicians working part-time in prehospital care, one could argue that as long as we do not have special rapid response units handling major disasters, a skill level of 3 or less is, in reality, insufficient for most physicians.
Cross-referencing the self-assessed skill levels in the use of the radio with the number of hours of training received suggests that there is something to be gained by increasing the amount of training offered to physicians working in prehospital care. As seen in figure 3, there were no users claiming level 1 competency among physicians who had received in excess of 3 hours of training. Similarly, the percentage of physicians with a self-assessment of level 4 competency increased in line with the amount of training received; in fact, over $60 \%$ of physicians $(62 \%)$ who had received in excess of 5 hours training registered a level 4 competency.

This study does not show causality between the amount of training received in the use of the equipment and the resulting level of skill using the authority radio. However, it does reveal enhanced skill levels in the use of the TETRA radio for communication among those physicians who received the most training in its use, indicating that causality may exist. A prior study in other settings has shown similar results, finding significantly greater cardiopulmonary resuscitation knowledge and skills among physicians with prior training. ${ }^{28}$

We speculate that the current skill levels in the use of the tools available for prehospital communication are insufficient to ensure that all physicians are fully able to concentrate on their primary task, namely providing optimal medical care for patients. The majority of physicians are currently sufficiently equipped to handle radio communication but the competencies of a substantial minority need to be improved.

Further studies are required to investigate how best to achieve acceptable skill levels among operators of the prehospital authority radio. However, the effect of combining hands-on training with e-learning has previously been shown to be effective as a tool for acquiring practical skills in prehospital care. ${ }^{9}$ If the positive effects of training can be demonstrated, we propose that a national set of requirements be implemented, standardising minimum requirements for training in the use of the TETRA radio, which must be completed prior to starting work in prehospital care.

\section{Strengths and limitations}

As the TETRA standard has already been fully implemented across the whole of Scandinavia, as well as large parts of Europe including Germany and the UK, ${ }^{729}$ and as more and more EMS around the world are converting to this standard, the results of this study ought to be applicable outside a Danish context.

There are some known limitations to this study. A response rate of $74 \%$ in a study by questionnaire is relatively high but an even higher response rate might have been achievable in different circumstances.

Assuming that non-responders are likely to belong to groups possessing lower levels of competency in the use of the radio, there is a known bias inherent in this study.

Although this study aimed to include all physicians in Denmark working with $24 / 7 / 365$ operational RRVs or HEMS, it is possible that we did not succeed in this aim. 
Regarding the need for formalised training in the use of equipment used for radio communication in prehospital care, while we have shown that self-assessed skills in the use of the TETRA radio are below average for almost a third of physicians in the study and although we have pointed out a lack of formal training in the use of the equipment, it still remains to be seen whether there is a direct causal relationship between an increase in the provision of formal training and the self-assessed levels of physicians' skill in using the equipment.

\section{CONCLUSION}

As the first study in its field, this study investigated the training received in the use of essential communication equipment among physicians working in prehospital care in Denmark. It showed that competency in the use of essential communication equipment may not have been as highly prioritised as other technical skills needed to work in a prehospital setting. For the majority of physicians, the current level of training results in skills sufficient for the use of the TETRA radio for everyday use; however, for a substantial minority further training is needed, especially if the redundancy of the prehospital system is to be preserved. Competency in prehospital radio communication needs to be acquired and maintained alongside the rest of the technical skills needed to function in this environment.

Contributors The author is responsible for all aspects of the conception and production of this article.

Competing interests None declared.

Patient consent Detail has been removed from this case description to ensure anonymity. The editors and reviewers have seen the detailed information available and are satisfied that the information backs up the case the author is making.

Provenance and peer review Not commissioned; externally peer reviewed.

Data sharing statement All data from the survey are available as supplementary files.

Open Access This is an Open Access article distributed in accordance with the Creative Commons Attribution Non Commercial (CC BY-NC 4.0) license, which permits others to distribute, remix, adapt, build upon this work non-commercially, and license their derivative works on different terms, provided the original work is properly cited and the use is non-commercial. See: http://creativecommons.org/ licenses/by-nc/4.0/

(C) Article author(s) (or their employer(s) unless otherwise stated in the text of the article) 2017. All rights reserved. No commercial use is permitted unless otherwise expressly granted.

\section{REFERENCES}

1. Harmsen AM, Giannakopoulos G, Franschman G, et al. Limitations in prehospital communication between trauma helicopter, ambulance services, and dispatch centers. J Emerg Med 2017;52:504-12.

2. Seppänen $H$, Mäkelä J, Luokkala $P$, et al. Developing shared situational awareness for emergency management. Saf Sci 2013;55:1-9.
3. Norri-Sederholm T, Paakkonen H, Kurola J, et al. Situational awareness and information flow in prehospital emergency medical care from the perspective of paramedic field supervisors: a scenariobased study. Scand J Trauma Resusc Emerg Med 2015;23:4.

4. Briggs A, Raja AS, Joyce MF, et al. The role of nontechnical skills in simulated trauma resuscitation. J Surg Educ 2015;72:732-9.

5. Regeringen. Et robust og sikkert samfund - Regeringens politik for beredskabet i Danmark. Forsvarsministeriet, editor, 2005.

6. LBK 262 af 22 april. Bekendtgørelse om radiokommunikationsnet. 20082008.

7. Vejledning til bekendtgørelse 262 af 22 APR 2008, 2011.

8. Abelsson A, Rystedt I, Suserud BO, et al. Mapping the use of simulation in prehospital care - a literature review. Scand J Trauma Resusc Emerg Med 2014;22:22.

9. Krogh CL, Steinmetz J, Rudolph SS, et al. Effect of ultrasound training of physicians working in the prehospital setting. Scand $J$ Trauma Resusc Emerg Med 2016;24:99.

10. Noble VE, Lamhaut L, Capp R, et al. Evaluation of a thoracic ultrasound training module for the detection of pneumothorax and pulmonary edema by prehospital physician care providers. BMC Med Educ 2009;9:3.

11. Walcher F, Kirschning T, Brenner F, et al. [Training in emergency sonography for trauma. concept of a 1-day course program]. Anaesthesist 2009;58:375-8.

12. von Elm E, Altman DG, Egger M, et al. The Strengthening the Reporting of Observational studies in Epidemiology (STROBE) statement: guidelines for reporting observational studies. J Clin Epidemiol 2008;61:344-9.

13. Vandenbroucke JP, von Elm E, Altman DG, et al. Strengthening the Reporting of Observational studies in Epidemiology (STROBE): explanation and elaboration. Epidemiology 2007;18:805-35.

14. McColl E, Jacoby A, Thomas L, et al. Design and use of questionnaires: a review of best practice applicable to surveys of health service staff and patients. Health Technol Assess 2001;5:1-256.

15. Jensen HI, Ammentorp J, Erlandsen M, et al. End-of-life practices in danish ICUs: development and validation of a questionnaire. BMC Anesthesiol 2012;12:16.

16. Rattray J, Jones MC. Essential elements of questionnaire design and development. J Clin Nurs 2007;16:234-43.

17. Competencies Proficiency Scale - Office of Human Resources at the US National Institute of Health. 2016. https://hr.od.nih.gov/ workingatnih/competencies/proficiencyscale.htm.

18. Andersen SA. Virtual reality simulation training of mastoidectomy studies on novice performance. Dan Med J 2016;63.

19. Rebolledo BJ, Hammann-Scala J, Leali A, et al. Arthroscopy skills development with a surgical simulator: a comparative study in orthopaedic surgery residents. Am J Sports Med 2015;43:1526-9.

20. Carbonne B, Sabri-Kaci I. Assessment of an e-learning training program for cardiotocography analysis: a multicentre randomized study. Eur J Obstet Gynecol Reprod Biol 2016;197:111-5.

21. Davies A, Macleod R, Bennett-Britton I, et al. E-learning and nearpeer teaching in electrocardiogram education: a randomised trial. Clin Teach 2016;13:227-30.

22. Jensen ML, Mondrup F, Lippert F, et al. Using e-learning for maintenance of ALS competence. Resuscitation 2009;80:903-8.

23. Mulla M, Sharma D, Moghul M, et al. Learning basic laparoscopic skills: a randomized controlled study comparing box trainer, virtual reality simulator, and mental training. J Surg Educ 2012;69:190-5.

24. Scott DJ, Bergen PC, Rege RV, et al. Laparoscopic training on bench models: better and more cost effective than operating room experience? J Am Coll Surg 2000;191:272-83.

25. Beard JH, Akoko L, Mwanga A, et al. Manual laparoscopic skills development using a low-cost trainer box in Tanzania. J Surg Educ 2014;71:85-90.

26. Montoya-Chinchilla R, Campillo-Soto A, Pietricica B, et al. [Low-cost laparoscopic training: necessary time for acquiring expertise]. Cir Cir 2012;80:253-60.

27. Rizan C, Ansell J, Tilston TW, et al. Are general surgeons able to accurately self-assess their level of technical skills? Ann R Coll Surg Engl 2015;97:549-55.

28. Curry L, Gass D. Effects of training in cardiopulmonary resuscitation on competence and patient outcome. CMAJ 1987;137:491-6.

29. Terrestrial tranked radio. http://en.wikipedia.org2017https://en. wikipedia.org/wiki/Terrestrial_Trunked_Radio. 